\title{
WHEN SMOKING CESSATION IS NOT A FRIEND OF YOURS MENTAL ILLNESS
}

\author{
Ana Cristina Mendes Silva, USF São Martinho de Pombal, PORTUGAL
}

\section{INTRODUCTION}

Health care providers are urged to facilitate smoking cessation for patients who smoke, but the effects of smoking cessation on the metabolism of some drugs is not routinely considered. Numerous drug interactions exist with smoking. Therefore, smokers taking a medication that interacts with smoking may require higher dosages than non-smokers. Conversely, upon smoking cessation, smokers may require a reduction in the dosage of an interacting medication. Polycyclic aromatic hydrocarbons found in tobacco smoke are potent inducers of the hepatic cytochrome P-450 (CYP) isoenzymes $1 \mathrm{~A} 1,1 \mathrm{~A} 2$, and, possibly, 2E1. After a person quits smoking, an important consideration is how quickly the induction of CYP1A2 dissipates. The primary pharmacokinetic interactions with smoking occur with drugs that are CYP1A2 substrates, such as caffeine, clozapine, fluvoxamine, olanzapine, tacrine, and theophylline. Smoking cessation reverses smoking-induced CYP1A2 hepatic enzyme levels to normal, increasing plasma concentrations in patients whose dose was established while smoking. In that patients, varenicline and bupropion are recommended for nicotine-dependence.

This is particularly important in schizophrenic patients, just because smoking prevalence for them is higher than this for general population.

Olanzapine is an atypical antipsychotic drug approved for the treatment of schizophrenia and mania and for preventing the recurrence of bipolar disorders. It is a thienobenzodiazepine derivate, extensively metabolised in the liver, approximately 50 $60 \%$ by CYP1A2.

\section{CASE REPORT}

I report the case of a 37 years-old man, who smokes 25 cigarettes per day, single and computer engineer, with the diagnosis of subchronic psychosis schizoaffective established since a lot of years with antipsychotic treatment, olanzapine $15 \mathrm{mg}$ per day, without more personal or family medical history relevant.
The patient presented with anxiety, tiredness, a little drowsiness and more social isolation than usual. After conversation, I notice that symptoms started one week after he decided to abruptly stop smoking. I adjust antipsychotic treatment and he started a lower dosage of olanzapine (10mg per day) as well as, the antidepressant medication with a higher dosage of bupropion (double dose - 300mg per day). After 4 days, he showed a good evolution of his symptoms, feeling much better, with more activity, with his mental illness apparently controlled and proud of his decision to stop smoking.

\section{DISCUSSION}

When patients stop smoking, providers should carefully review prescribed drug regimens and adjust or monitor drugs whose metabolism is affected by smoking cessation, because it may increase plasma levels of some drugs to potentially toxic levels. This is particularly important for patients who abruptly stop smoking.

Respecting to olanzapine, smoking-induced increased CYP1A2 activity significantly diminished plasma concentrations and the antipsychotic effect of the drug. Some studies comment that a daily consumption of 7-12 cigarettes is probably sufficient for maximum induction of olanzapine metabolism. A 50\% lower starting dose in non-smokers seems rational to obtain an equivalent olanzapine concentration and avoid side effects. A meta-analysis suggest that the daily doses of olanzapine should be reduced by $30 \%$ in non-smokers compared with smokers.

This case shows us that smoking is one of the factors of importance for the pharmacokinetic variability of olanzapine, and the therapeutic drug monitoring is an important tool in the clinical follow-up of antipsychotic treatment.

\section{SOURCES}

Schaffer SD, Yoon S, Zadezensky I. A review of smoking cessation: potentially risky effects on prescribed medications. J Clin Nurs. 2009 Jun;18(11):1533-40. doi: 10.1111/j.1365-2702.2008.02724.x. Review. PubMed PMID: 19490292

Botts S, Diaz FJ, et al. Estimating the effects of co-medications on plasma olanzapine concentrations by using a mixed model. Prog Neuropsychopharmacol Biol Psychiatry. 2008 Aug 1;32(6):1453-8. doi: 10.1016/j.pnpbp.2008.04.018. Epub 2008 May 7. PubMed PMID: 18555573

Carrillo JA, Herráiz AG, Ramos SI, Gervasini G, Vizcaíno S, Benítez J. Role of the smoking-induced cytochrome P450 (CYP)1A2 and polymorphic CYP2D6 in steady-state concentration of olanzapine. J Clin Psychopharmacol. 2003 Apr;23(2):119-27. PubMed PMID: 12640212

Haslemo T, Eikeseth $\mathrm{PH}$, Tanum L, Molden E, Refsum H. The effect of variable cigarette consumption on the interaction with clozapine and olanzapine. Eur J Clin Pharmacol. 2006 Dec;62(12):1049-53. Epub 2006 Nov 7. PubMed PMID: 17089108 Kroon LA. Drug interactions with smoking. Am J Health Syst Pharm. 2007 Sep. 15;64(18):1917-21. Review. PubMed PMID: 17823102 Mendelsohn CP, Kirby DP, Castle DJ. Smoking and mental illness. An update for psychiatrists. Australas Psychiatry. 2015 Feb;23(1):37-43. doi: 10.1177/1039856214562076. Epub 2014 Dec 15. Review. PubMed PMID: 25512967 